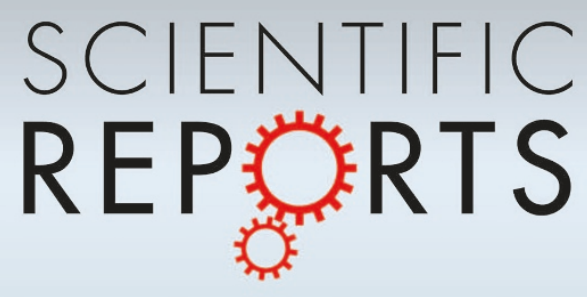

OPEN

SUBJECT AREAS:

ELECTROCATALYSIS

HETEROGENEOUS CATALYSIS

Received

27 March 2014

Accepted

11 June 2014

Published

30 June 2014

Correspondence and requests for materials should be addressed to J.S.L. (jlee1234@unist. ac.kr)

* These authors contributed equally to this work.

\title{
Fabrication of graphene-based electrode in less than a minute through hybrid microwave annealing
}

\author{
Duck Hyun Youn ${ }^{1 *}$, Ji-Wook Jang ${ }^{1 *}$, Jae Young Kim', Jum Suk Jang ${ }^{2}$, Sun Hee Choi ${ }^{3} \&$ Jae Sung Lee ${ }^{1}$
}

\begin{abstract}
'School of Nano-Bioscience and Chemical Engineering, Ulsan National Institute of Science and Technology (UNIST), Ulsan 689798 Korea, ${ }^{2}$ Division of Biotechnology, College of Environmental and Bioresource Sciences, Chonbuk National University, Iksan 570-752, Korea, ${ }^{3}$ Pohang Accelerator Laboratory (PAL), Pohang University of Science and Technology (POSTECH), Pohang 790784 , Korea.
\end{abstract}

Highly efficient and stable $\mathrm{MoS}_{2}$ nanocrystals on graphene sheets $\left(\mathrm{MoS}_{2} / \mathrm{GR}\right)$ are synthesized via a hybrid microwave annealing process. Through only 45 second-irradiation using a household microwave oven equipped with a graphite susceptor, crystallization of $\mathrm{MoS}_{2}$ and thermal reduction of graphene oxide into graphene are achieved, indicating that our synthetic method is ultrafast and energy-economic. Graphene plays a crucial role as an excellent microwave absorber as well as an ideal support material that mediates the growth of $\mathrm{MoS}_{2}$ nanocrystals. The formed $\mathrm{MoS}_{2} / \mathrm{GR}$ electrocatalyst exhibits high activity of hydrogen evolution reaction with small onset overpotential of $0.1 \mathrm{~V}$ and Tafel slope of $50 \mathrm{mV}$ per decade together with an excellent stability in acid media. Thus our hybrid microwave annealing could be an efficient generic method to fabricate various graphene-based hybrid electric materials for broad applications.

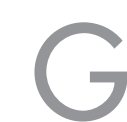

raphene, two-dimensional carbon material, possesses unique properties such as excellent electrical and thermal conductivities, good mechanical strength, and high specific surface area ${ }^{1,2}$. Owing to its excellent properties, graphene has been regarded as an ideal component to fabricate electrode materials in the field of energy conversion and storage. In particular, various combinations of graphene and inorganic metal compounds, graphene-based hybrid electrodes, have attracted tremendous attraction in a broad range of applications including fuel cells ${ }^{3}$, batteries ${ }^{4}$, supercapacitors ${ }^{5}$, photocatalysts ${ }^{6}$, and solar cells ${ }^{7}$ because graphene can enhance the electrocatalytic activities of immobilized metal compounds.

Fabrication methods of graphene-based hybrid electrodes are critical for their performance as emphasized in several recent reviews ${ }^{8-10}$. For graphene-based hybrid electrodes for energy related systems, graphene oxide (GO) derived from graphite is the preferred starting material due to low cost and high yield compared to higher quality but expensive pure graphene produced from epitaxial growth or chemical vapor deposition. In general, graphenemetal hybrid electrodes can be prepared by the reduction of metal precursors using a reducing agent like $\mathrm{NaBH}_{4}$ or via electrochemical reduction. On the other hand, graphene-metal oxide, sulfide, phosphate hybrid electrodes can be synthesized by various methods in the presence of $\mathrm{GO}^{9}$. For example, $\mathrm{TiO}_{2}$ nanoparticles on reduced graphene oxide $\left(\mathrm{TiO}_{2} / \mathrm{RGO}\right)$ hybrid was synthesized by hydrothermal method at $120^{\circ} \mathrm{C}$ for $3 \mathrm{~h}$ and CdS/RGO by solvothermal method $180^{\circ} \mathrm{C}$ for $12 \mathrm{~h}$ in DMSO as a solvent $t^{6,11}$. In addition, $\mathrm{Co}(\mathrm{OH})_{2} / \mathrm{RGO}$ was prepared via reflux at $83^{\circ} \mathrm{C}$ for $4 \mathrm{~h}$ using isopropyl alcohol and $\mathrm{Na}_{2} \mathrm{~S}$ as a solvent and reducing agent respectively ${ }^{5}$. A precipitation followed by calcination method was used to synthesize $\mathrm{Fe}_{2} \mathrm{O}_{3} / \mathrm{RGO}^{12}, \mathrm{SnO}_{2} / \mathrm{RGO}^{13}$, and $\mathrm{LiFePO}_{4} / \mathrm{RGO}$ hybrid electrodes ${ }^{4}$. However, these general synthetic routes including hydrothermal, solvothermal, reflux, and calcination techniques are rather complex or time- and energy- consuming, and require high temperatures, hourscale reaction times, and various reaction steps. Therefore, we need to develop a more facile approach for the synthesis of graphene-based hybrid electrodes.

Microwave heating is an alternative method to fabricate the graphene-based hybrid electrodes. Compared to other synthetic routes, it is a more rapid heating process generating smaller and more uniform nanoparticles onto graphene with decreased reaction time. The microwave heating in general involves direct interactions of microwave with the atoms, ions and molecules of the material, thus the temperature of entire sample can be raised dramatically in a very short time ${ }^{14} \cdot \mathrm{Mn}_{3} \mathrm{O}_{4} /$ graphene and $\mathrm{NiCo}_{2} \mathrm{O}_{4} /$ graphene hybrid electrodes were prepared by microwave assisted hydrothermal method at $200^{\circ} \mathrm{C}$ for $5 \mathrm{~h}^{15}$. Various graphene-metal sulfides such as $\mathrm{ZnS}$, CdS, 
$\mathrm{Ag}_{2} \mathrm{~S}$, and $\mathrm{Cu}_{2} \mathrm{~S}$ electrodes were synthesized by microwave heating for $\sim 15$ min using ethylene glycol as a solvent, microwave absorbent, and reducing agent of $\mathrm{GO}^{16}$.

Although the solvent-based microwave reaction has an advantage of a shorter reaction time than the usual thermal methods, it has drawbacks of non-uniform heating and presence of an upper limit in the reaction temperature since most of irradiated microwave is absorbed by solvent. In addition, most of non-conducting materials cannot efficiently absorb the low frequency $(2.45 \mathrm{GHz})$ household microwave at room temperature due to their low dielectric properties and high attenuation distance. Thus, further shortening of the reaction time down to minute- or second-scale is difficult in solventbased microwave reaction. Here we report for the first time an extremely simple, ultrafast (less than $1 \mathrm{~min}$ ), and energy-economic 'hybrid microwave anneaning (HMA)' synthesis of the graphenebased hybrid electrodes.

The HMA (Figure 1) combines this microwave heating with an additional heating from an effective microwave absorber (susceptor $)^{17,18}$. Upon microwave irradiation, the temperature of a susceptor (graphite in our case) increased dramatically first and the susceptor transfers the heat to the target material via the conventional heating mechanisms. Then, the target materials could absorb microwave effectively due to the changed dielectric properties and attenuation distance at the elevated temperature ${ }^{18}$. This combined action of microwaves and microwave-coupled external heating source in HMA system has been mainly used for sintering ceramics ${ }^{19-22}$. Surprisingly, however, it is rarely used for the chemical synthesis process to the best of our knowledge.

Molybdenum disulfide $\left(\mathrm{MoS}_{2}\right)$ of a two-dimensional layered structure exhibits unique electronic, optical, mechanical, and chemical properties ${ }^{23}$, which have attracted a wide range of interest encompassing catalysis ${ }^{24,25}$, batteries ${ }^{26}$, electronics ${ }^{27}$, photocatalysis ${ }^{28}$, and solar cells ${ }^{29}$. In recent years, $\mathrm{MoS}_{2}$ has been proven to be an active electrocatalyst for hydrogen evolution reaction (HER), which is traditionally catalyzed by expensive and scarce platinum ${ }^{30-36}$. Hence, we selected $\mathrm{MoS}_{2} / \mathrm{GR}$ hybrid electrode as a target system to apply the HMA fabrication process.

In this report, we used the HMA process to fabricate $\mathrm{MoS}_{2} / \mathrm{GR}$ (75 wt $\% \mathrm{MoS}_{2}$ ) as an efficient HER electrocatalyst. Here, the graphite susceptor initiates the reaction including thermal reduction of GO to GR, and as a good microwave absorber GR further facilitates the reaction by effectively absorbing the microwave ${ }^{37}$. Hence, GR in the $\mathrm{MoS}_{2} / \mathrm{GR}$ becomes an additional susceptor imbedded in the sample, which is more effective because of close contact with $\mathrm{MoS}_{2}$. In HER, the obtained $\mathrm{MoS}_{2} / \mathrm{GR}$ hybrid showed a good onset potential of $c a$. $0.1 \mathrm{~V}$ and Tafel slope value of $50 \mathrm{mVdec}^{-1}$. The performance represents one of the best values in $\mathrm{HER}$ by $\mathrm{MoS}_{2}$-based catalysts. In the HMA process, crystallization of $\mathrm{MoS}_{2}$ and reduction of GO occur at the same time in extremely short treatment time of only 45 seconds in a household microwave oven. Thus, our $\mathrm{MoS}_{2} / \mathrm{GR}$ hybrid synthesized by the novel method proposed here could be a promising electrocatalyst for HER, and the process could be applied to synthesis of various other graphene-based hybrid electrical materials for many applications.

\section{Results}

Physicochemical properties of $\mathrm{MoS}_{2} / \mathrm{GR}$ hybrid. Figure 1 illustrates schematically the synthetic method for $\mathrm{MoS}_{2} / \mathrm{GR}$ hybrid electrocatalysts. By simply mixing $\mathrm{MoCl}_{5}, \mathrm{GO}$, thiourea, and ethanol in one pot, it is possible to generate a precursor state of metal-thiourea complex. The metal precursor reacts with ethanol vigorously, releasing major part of the chlorine as $\mathrm{HCl}$ and generating molybdenum orthoester ${ }^{37}$. By adding thiourea, a viscous Mothiourea complex is formed on GO. After the evaporation of ethanol, the glass reactor is purged with argon gas to drive out a small amount of remaining oxygen. The reactor is moved onto graphite susceptor and the microwave reaction proceeds just for 45 seconds. The temperature of the system increases up to $\sim 700^{\circ} \mathrm{C}$ during the reaction occurring under dry inert gas conditions. Thus the graphite susceptor absorbs the microwave $(2.45 \mathrm{GHz})$ and generated heat that is transferred to the precursors by the conventional heat transfer mechanisms (Heat I). Then the heated precursor effectively absorbs the microwave energy by its modified dielectric properties and attenuation distance (Heat II). Besides, GO is reduced thermally to GR by releasing the oxygen functional groups of GO in the form of $\mathrm{CO}$ or $\mathrm{CO}_{2}{ }^{38}$. In turn, GR acts as a good absorber for microwave and facilitates further the $\mathrm{MoS}_{2}$ crystallization (Heat III) ${ }^{39}$. During the 45 seconds of HMA, these three kinds of heat (I-III) contribute to crystallization of $\mathrm{MoS}_{2}$ and reduction of GO. In comparison, crystallization of $\mathrm{MoS}_{2}$ was observed in a minute even without GO. However, without applying graphite susceptor, crystalline $\mathrm{MoS}_{2}$ was not formed even after 1 hour, indicating the decisive role of graphite susceptor in the HMA process.

Figure 2 compares the XRD patterns of $\mathrm{MoS}_{2} / \mathrm{GR}$ hybrid with those of bare $\mathrm{MoS}_{2}$ synthesized without GO. The inset denotes the XRD patterns of the pristine GO and synthesized GR via HMA method without metal precursor. As indicated, the XRD patterns of the synthesized catalysts are gnerally consistent with the reference XRD pattern of hexagonal $\mathrm{MoS}_{2}$ (JCPSD 01-075-1539). No other phases were detected and hence $\mathrm{MoS}_{2}$ is the dominant phase. The $\mathrm{MoS}_{2}$ in $\mathrm{MoS}_{2} / \mathrm{GR}$ has better crystallinity than that of bare $\mathrm{MoS}_{2}$, showing the beneficial effect of GR as an imbedded secondary

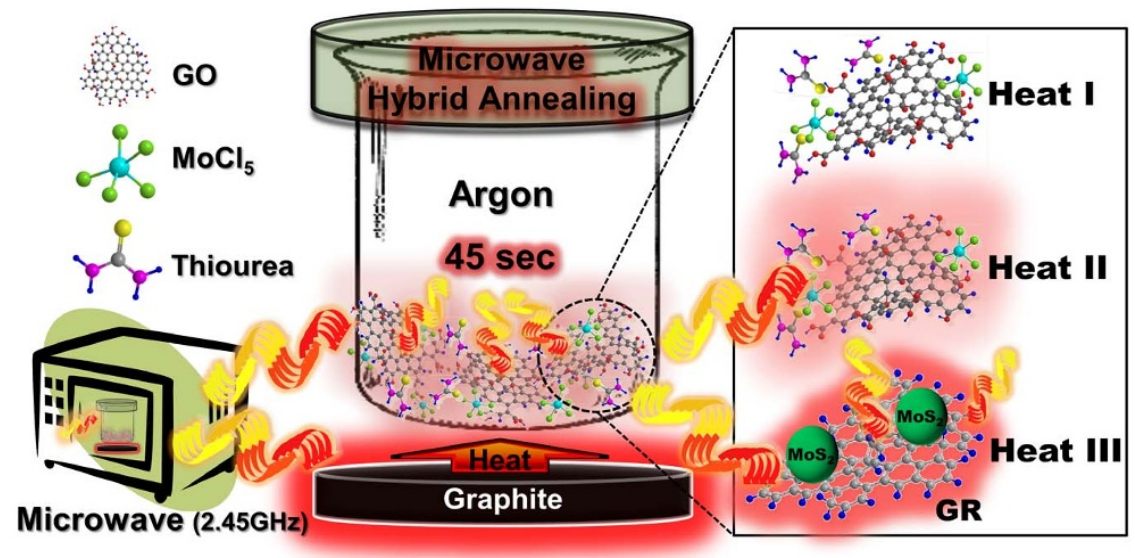

Figure 1 Schematic illustration of the hybrid microwave annealing (HMA) system to prepare $\mathrm{MoS}_{2} /$ GR composite catalyst. Magnified images (right) represent the three different heats involved in crystallization of $\mathrm{MoS}_{2}$ and reduction of graphene oxide. 


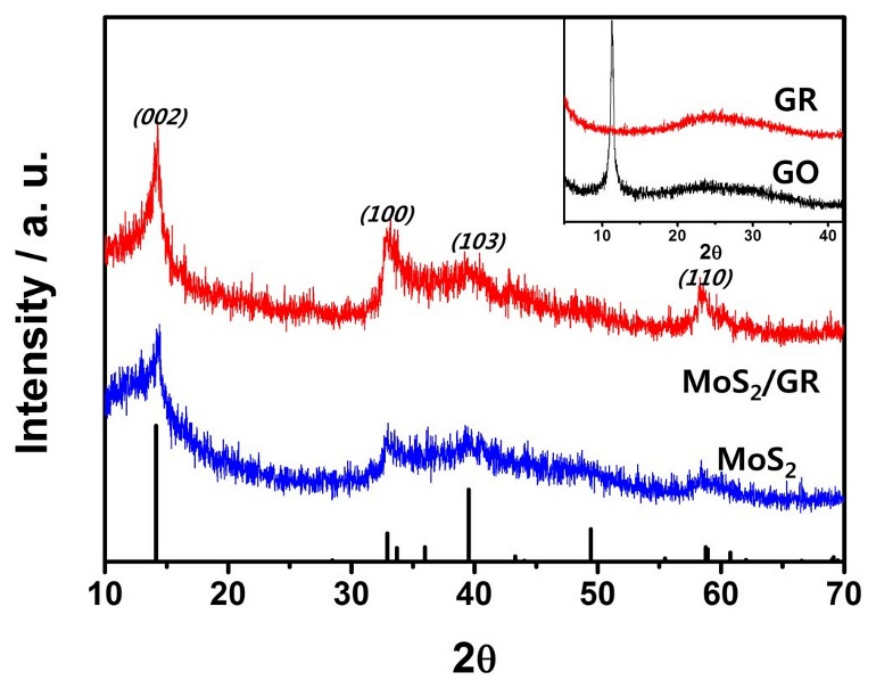

Figure $2 \mid$ XRD patterns of synthesized $\mathrm{MoS}_{2} / \mathrm{GR}$ and bare $\mathrm{MoS}_{2}$. Vertical lines indicate reference pattern of $\mathrm{MoS}_{2}$ (JCPDS 01-075-1539). The inset shows XRD patterns of the pristine GO and synthesized GR by HMA.

susceptor during the HMA process for crystallization of $\mathrm{MoS}_{2}$. The (002) peak at $14^{\circ}$ originates from stacking layers confirming the layered structure of $\mathrm{MoS}_{2}$. The absence of the peak around $11^{\circ}$ in $\mathrm{MoS}_{2}$ samples indicates that the reduction of GO to GR by microwave irradiation, which will be further demonstrated by Raman and XPS measurements later.

Structural details of $\mathrm{MoS}_{2} / \mathrm{GR}$ were investigated by TEM analyses. $\mathrm{MoS}_{2}$ nanocrystals consisting of $4 \sim 10$ layers are dispersed on GR in Figure $3 \mathrm{a}$ and Figure S1a. The free-standing $\mathrm{MoS}_{2}$ nanocrystals staying away from the GR sheets are not seen. HR-TEM image (inset of Figure 3a) shows that $\mathrm{MoS}_{2}$ has a layered structure with an interlayer distance of $0.624 \mathrm{~nm}$, which corresponds to (002) plane of hexagonal $\mathrm{MoS}_{2}{ }^{26,28}$. In stark contrast to $\mathrm{MoS}_{2} / \mathrm{GR}$ hybrid, bare $\mathrm{MoS}_{2}$ exhibits highly aggregated nanocrystals of $\mathrm{MoS}_{2}$ (Figure $3 \mathrm{~b}$ and Figure S1b). The dark parts of the TEM image originate from the aggregation of $\mathrm{MoS}_{2}$ nanocrystals. Electron energy loss spectroscopy (EELS) of TEM provides further morphological information of $\mathrm{MoS}_{2} / \mathrm{GR}$ hybrid. Figure $3 \mathrm{e}$ and $3 \mathrm{f}$ show the elemental mapping images of sulfur and molybdenum, which are perfectly consistent with that of carbon in Figure 3d, confirming that GR sheets are uniformly decorated with $\mathrm{MoS}_{2}$ nanocrystals. The corresponding EELS spectra of $\mathrm{MoS}_{2} / \mathrm{GR}$ are displayed in Figure S2, which demonstrate the existence of Mo, S, and C in the sample.

Similar results were obtained from SEM analyses in Figure S3. The SEM images of $\mathrm{MoS}_{2}$ /GR hybrid exhibit a wrinkled paper-like morphology of GR. Although $\mathrm{MoS}_{2}$ nanoparticles are not seen in this image, energy dispersive spectroscopy (EDS) measurements in Figure S3b reveal the presence of $\mathrm{MoS}_{2}$ on the surface of GR with ca. $1: 2$ molar ratio of Mo and S. Furthermore, EDS mapping images in Figure S4 strongly support that GR layers are uniformly covered with $\mathrm{MoS}_{2}$ nanocrystals. In contrast, bare $\mathrm{MoS}_{2}$ nanocrystals are severely aggregated each other in Figure S3c, which is similar to the bulk structure of commercial $\mathrm{MoS}_{2}$ from Aldrich shown in Figure S3d. The morphological difference between $\mathrm{MoS}_{2} / \mathrm{GR}$ hybrid and bare $\mathrm{MoS}_{2}$ observed by TEM and SEM demonstrates the importance of GR as an ideal support material for mediating the growth of $\mathrm{MoS}_{2}$ nanocrystals. Oxygen-containing functional groups on GO attract the metal precursor, and thus growth of $\mathrm{MoS}_{2}$ occurs on GR layers selectively. Furthermore, a strong interaction between $\mathrm{MoS}_{2}$ and GR could alleviate the aggregation of $\mathrm{MoS}_{2}$ nanocrystals ${ }^{33,40-42}$.

Conductivities of the synthesized catalysts were measured by the four point probe method and the results are summarized in Table 1.
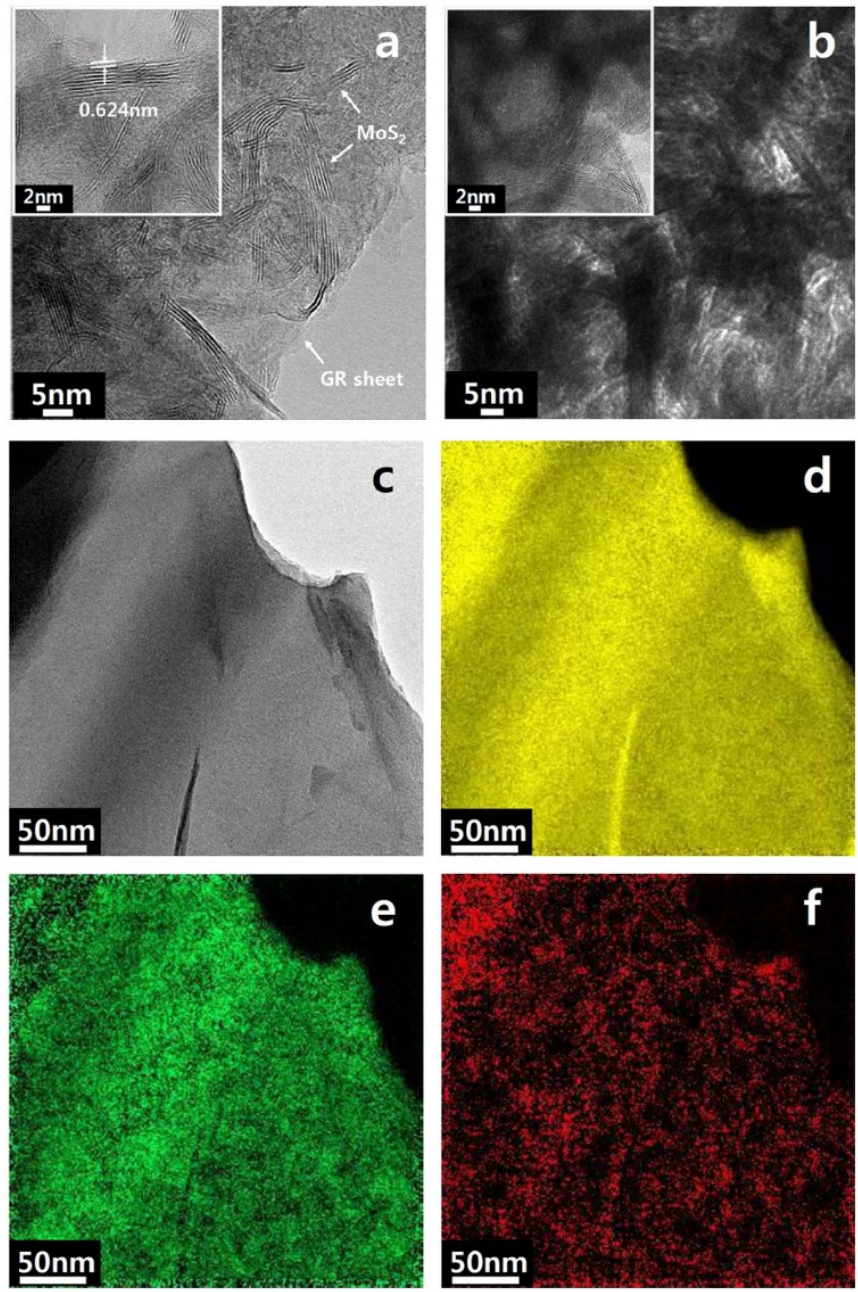

Figure 3 TEM images and the corresponding high-resolution TEM images of (a) $\mathrm{MoS}_{2} / \mathrm{GR}$ and (b) bare $\mathrm{MoS}_{2}$. Element mapping images of $\mathrm{MoS}_{2} / \mathrm{GR}$ using electron energy loss spectroscopy (EELS) for (c) raw image, (d) carbon, (e) sulfur, and (f) molybdenum.

Bare $\mathrm{MoS}_{2}$ itself is a very poor electrical conductor with its sheet resistance exceeding the measurement limit $\left(500 \times 10^{6} \Omega \square^{-1}\right)$. The commercial $\mathrm{MoS}_{2}$ (Aldrich) shows a measurable, but very large sheet resistance of $2.6 \times 10^{6} \Omega \square^{-1}$. The $\mathrm{MoS}_{2} / \mathrm{GR}$ hybrid exhibits a dramatically reduced (by a factor of $\sim 10^{6}$ !) sheet resistance of $4 \Omega \square \square^{-1}$. Thus the conductivity of $\mathrm{MoS}_{2} / \mathrm{GR}$ was $\sim 10^{5}$ times higher than that of commercial $\mathrm{MoS}_{2}$. During the microwave heating, GO is converted to GR and it is further reduced as GR itself absorbs the microwave effectively. The high conductivity of graphene is responsible for the good conductivity of $\mathrm{MoS}_{2} / \mathrm{GR}$. The good conductivity is an essential requirement for a high activity in electrocatalysis, which was easily achieved here by adopting GO to $\mathrm{MoS}_{2}$ with a brief microwave heating to convert GO to GR.

The reactions between Mo and thiourea were followed by infrared (IR) spectroscopy in Figure 4a. As Mo precursor $\left(\mathrm{MoCl}_{5}\right)$ was mixed with thiourea under ambient conditions, blue shift (from 730.9 to $715.5 \mathrm{~cm}^{-1}$ ) of the $\mathrm{C}=\mathrm{S}$ stretching peak and red shift (from 1473.3 to $1514.3 \mathrm{~cm}^{-1}$ ) of the $\mathrm{C}-\mathrm{N}$ stretching peak are observed. The results indicate the reduced and increased double bond characteristics of $\mathrm{C}=\mathrm{S}$ and $\mathrm{C}-\mathrm{N}$ bonds, respectively, indicating the bond formation between Mo (V) and S of thiourea ${ }^{43,44}$ to yield a Mo-thiourea complex. In the presence of GO with the Mo-thiourea complex (GO-Mothiourea), the shape and position of $\mathrm{NH}_{2}$ stretching peaks at $2800 \sim$ $3700 \mathrm{~cm}^{-1}$ are different from those of Mo-thiourea. Also, the $\mathrm{C}=\mathrm{O}$ stretching peak is shifted from 1623.8 to $1608.3 \mathrm{~cm}^{-1}$ compared to 
Table 1 | Electrical properties of $\mathrm{MoS}_{2}$ and $\mathrm{MoS}_{2} /$ GR composite

\begin{tabular}{lcccr} 
Catalyst & $\begin{array}{c}\text { Sheet Resistance } \\
\left(\Omega \square^{-1}\right)\end{array}$ & $\begin{array}{c}\text { Conductivity } \\
\left(\mathrm{Sm}^{-1}\right)\end{array}$ & $\begin{array}{c}\mathrm{R}_{\mathrm{ct}}^{\mathrm{b}} \\
(\Omega)\end{array}$ & $\begin{array}{c}\text { Capacitance } \\
(\mu \mathrm{F})\end{array}$ \\
\hline $\mathrm{MoS}_{2} / \mathrm{GR}$ & $4.09( \pm 0.07)$ & $6.11 \times 10^{2}$ & 35 & 1246 \\
$\mathrm{MoS}_{2}$ & $>500 \times 10^{6}$ & - & 1130 & 56.64 \\
$\mathrm{MoS}_{2}$ (Ald) & $2.60( \pm 0.06) \times 10^{6}$ & $1.92 \times 10^{-3}$ & 3600 & 16.81 \\
\hline${ }^{\circ}$ From 4-point probe method, ${ }^{b}$ Extracted from fitting electrochemical impedance spectra to an equivalent circuit. & \\
\hline
\end{tabular}

pristine $\mathrm{GO}$. The changes in $\mathrm{NH}_{2}$ and $\mathrm{C}=\mathrm{O}$ stretching peaks denote the strong interaction between GO with the Mo-thiourea complex. During the synthesis process of $\mathrm{MoS}_{2} / \mathrm{GR}$ hybrid, sulfur in thiourea and Mo precursor are combined into a Mo-thiourea complex as evidenced in IR results. In the presence of GO, the Mo precursor is attracted through oxygen functional groups of $\mathrm{GO}$, generating the GO-Mo-thiourea complex. Thus, essentially the same chemical transformation takes place on the GO layers.

In Raman spectra of Figure $4 \mathrm{~b}$, the $\mathrm{I}_{\mathrm{D}} / \mathrm{I}_{\mathrm{G}}$ peak ratio (1.29) of $\mathrm{GO}$ Mo-thiourea complex is higher than that of GO (0.9), indicating the increased disorders ${ }^{45}$. At the ambient temperature, the GO-Mothiourea complex is formed, but GO is yet to be reduced to GR. Thus, the increased $\mathrm{I}_{\mathrm{D}} / \mathrm{I}_{\mathrm{G}}$ peak ratio could be attributable mainly to the strong interaction between GO and Mo-thiourea complex, which results in the increased disorders ${ }^{46}$. These Raman results are generally consistent with the IR results as well as the results of TEM and SEM analyses. Upon HMA treatment, the Mo-thiourea complex turns into $\mathrm{MoS}_{2}$ as indicated by two prominent peaks of $\mathrm{MoS}_{2}$, an inplane mode $\left(\mathrm{E}_{2 \mathrm{~g}}, 382.0 \mathrm{~cm}^{-1}\right)$ and an out-of-plane mode $\left(\mathrm{A}_{1 \mathrm{~g}}\right.$, $\left.408.5 \mathrm{~cm}^{-1}\right)^{35}$. In addition, the $\mathrm{I}_{\mathrm{D}} / \mathrm{I}_{\mathrm{G}}$ ratio of 1.15 for $\mathrm{MoS}_{2} / \mathrm{GR}$ is higher than 0.9 for $G O$. The increased $I_{D} / I_{G}$ ratio indicates the formation of $\mathrm{GR}$ by reduction of $\mathrm{GO}^{47-49}$.

Chemical states of $\mathrm{MoS}_{2} / \mathrm{GR}$ composite were further investigated by XPS. In Mo 3d spectra, two dominant peaks at 233 and $229 \mathrm{eV}$ are assigned to $\mathrm{Mo}^{4+} 3 \mathrm{~d}_{3 / 2}$ and $3 \mathrm{~d}_{5 / 2}$, respectively ${ }^{33-35}$, which originate from $\mathrm{MoS}_{2}$ in Figure 4c. The shoulder peaks around $236 \mathrm{eV}$ originating from $\mathrm{Mo}^{6+} 3 \mathrm{~d}_{3 / 2}$ reveal the existence of amorphous $\mathrm{MoO}_{3}{ }^{50}$. The amorphous trace of $\mathrm{MoO}_{3}$ species, which should have been derived from exposure of the sample to air, hardly affects the local structure of $\mathrm{MoS}_{2}$ as discussed below. The C1s spectrum of $\mathrm{MoS}_{2} / \mathrm{GR}$ is presented in Figure $4 \mathrm{~d}$. Various peaks are observed at 284.8, 286.2, 287.8, and $289.0 \mathrm{eV}$, corresponding to $\mathrm{C}-\mathrm{C}, \mathrm{C}-\mathrm{O}, \mathrm{C}=\mathrm{O}$, and $\mathrm{C}(\mathrm{O}) \mathrm{O}$, respectively ${ }^{38}$. Typical GO has several oxygen-containing functional groups including hydroxyl, carboxyl, and epoxy groups, and thus it exhibits broad peaks in $280 \sim 290 \mathrm{eV}$ range as shown in Figure S5a. However, in Figure 4d, intensity of the peaks related with oxygencontaining functional groups decreases significantly to the level of pure GR (Figure S5b), suggesting the reduction of GO to GR. Thus, considering these results of XRD (absence of the peak around $11^{\circ}$ ), Raman (the increased $\mathrm{I}_{\mathrm{D}} / \mathrm{I}_{\mathrm{G}}$ ratio compared to GO), and XPS (the decreased intensity of the peaks for oxygen-containing functional groups), we could confirm that GO is effectively reduced to GR by HMA for 45 seconds.

The Fourier-transformed EXAFS spectra of $\mathrm{MoS}_{2}$ catalysts in Figure 5 show two distinct peaks; one (A) at 1.0-2.3 $\AA$ and the other (B) at 2.3-3.3 $\AA$. The peak A denotes the interaction of the nearest neighboring sulfur atoms with a central molybdenum atom and the peak B is attributed to Mo-Mo scattering, as revealed by FEFF cal-
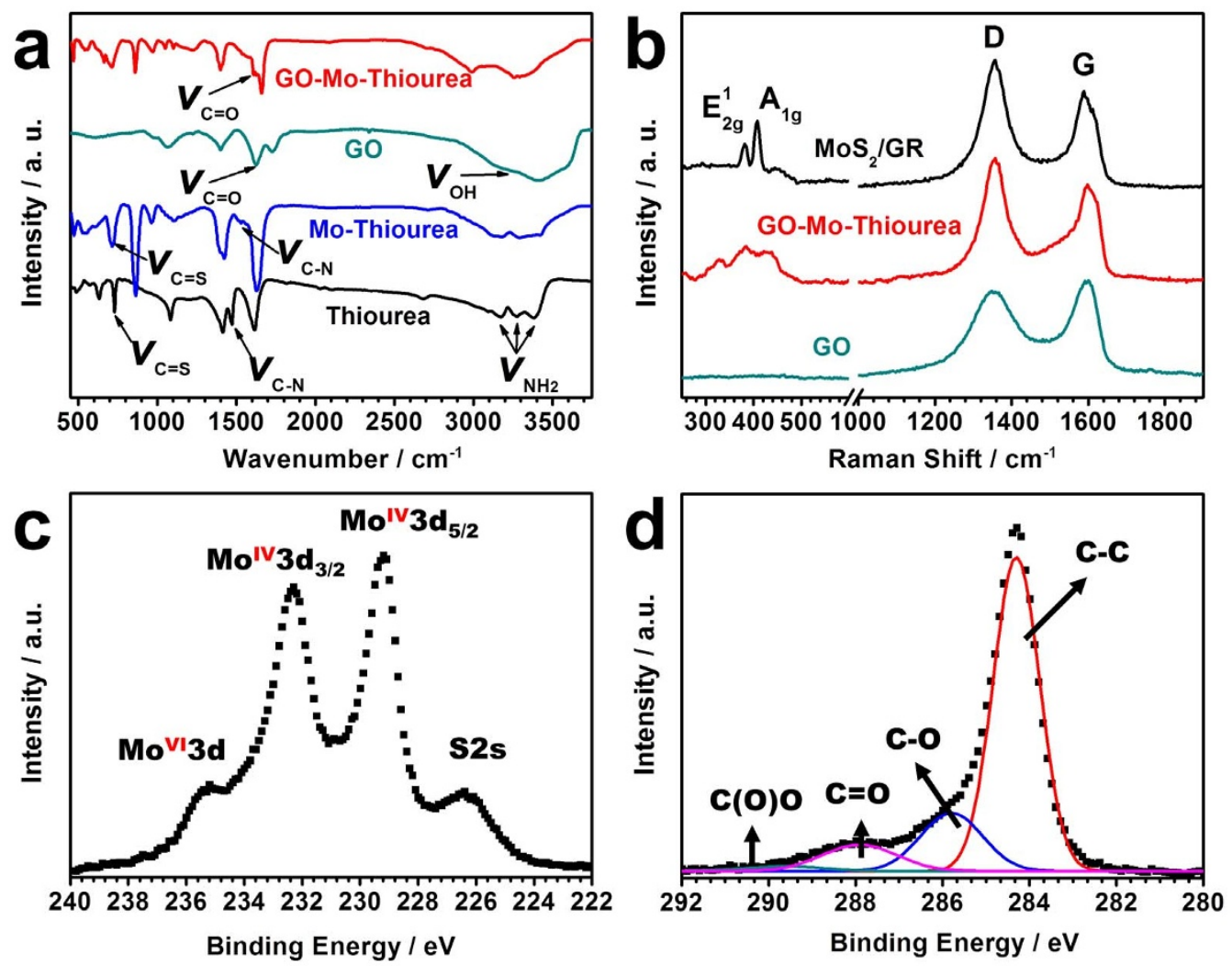

Figure 4 | (a) IR spectra of thiourea, GO, Mo-thiourea, and Go-Mo-thiourea complex. (b) Raman spectra of GO, Go-Mo-thiourea complex, and MoS 2 / GR. XPS spectra of $\mathrm{MoS}_{2} / \mathrm{GR}$ for (c) Mo 3d, (d) C 1 s. 


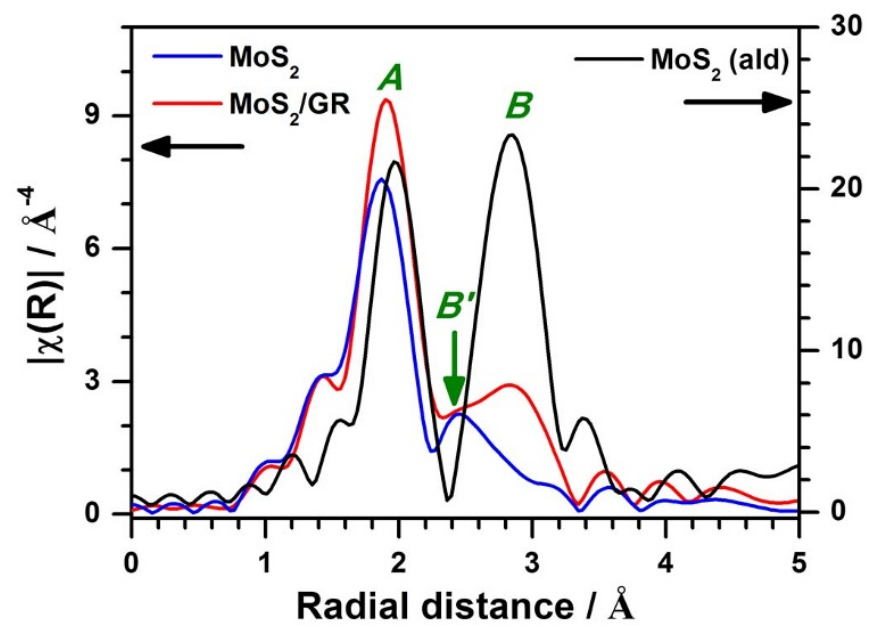

Figure $5 \mid$ Fourier-transforms of Mo K-edge EXAFS for synthesized $\mathrm{MoS}_{2}$ catalysts.

culation using known $\beta-\mathrm{MoS}_{2}$ crystal structure (space group p63/ $\mathrm{mmc})^{51}$. However, a new peak $\mathrm{B}^{\prime}$ at a shorter distance is developed when $\mathrm{MoS}_{2}$ and $\mathrm{MoS}_{2}$ /GR are synthesized by HMA. Particular attention should be paid to the fact that the intensity of peak $\mathrm{B}^{\prime}$ changes little but that of the peak B increases when $\mathrm{MoS}_{2}$ is supported on reduced graphene. The EXAFS least-square fitting results in Table 2 shows that the coordination number of the peak at 3.16-3.17 $\AA$ (due to the Mo-Mo distance of $\beta-\mathrm{MoS}_{2}$ crystal) increases from 0.2 to 1.6 and the one at a shorter distance remains unchanged with a large Debye-Waller factors of $>0.01 \AA^{2}$. The presence of the shorter MoMo distance together with the unusually large Debye-Waller factors for metal-metal scattering implies the amorphous nature of bare $\mathrm{MoS}_{2}$ catalysts, because the bonding strain can be relaxed at short distances in an amorphous structure ${ }^{52}$. More crystalline phase is created in $\mathrm{MoS}_{2} / \mathrm{GR}$ hybrid compared to bare $\mathrm{MoS}_{2}$, indicating that GR boosts $\mathrm{MoS}_{2}$ crystallization by acting as an effective microwave absorber $^{39}$ as well as a heat transfer medium. The result is consistent with XRD result in Figure 2. The increase in crystallinity of $\mathrm{MoS}_{2} / \mathrm{GR}$ is also reflected on the changes in distance and Debye-Waller factor of Mo-S scattering toward those of bulk $\mathrm{MoS}_{2}$ (Aldrich). And the EXAFS of the synthesized $\mathrm{MoS}_{2} / \mathrm{GR}$ and $\mathrm{MoS}_{2}$ in Figure 5 did not show any oxide-related peaks revealing surface oxide hardly affects the local structure of our $\mathrm{MoS}_{2}$ catalysts (Figure S6).

Hydrogen evolution reaction on $\mathrm{MoS}_{2} / \mathrm{GR}$ hybrid electrocatalyst. The $\mathrm{MoS}_{2} / \mathrm{GR}$ composites with varying amounts of $\mathrm{MoS}_{2}$ were screened for HER activity to find an optimum ratio between $\mathrm{MoS}_{2}$ and GR. In Figure S7, $\mathrm{MoS}_{2} / \mathrm{GR}$ with $75 \mathrm{wt} \% \mathrm{MoS}_{2}$ and $25 \mathrm{wt} \% \mathrm{GR}$ exhibited the best performance, and thus all $\mathrm{MoS}_{2} / \mathrm{GR}$ samples reported in this paper contain $75 \mathrm{wt} \% \mathrm{MoS}_{2}$ without specification. Figure 6 a depicts the polarization curves for HER of synthesized catalysts as well as a commercial Pt/C catalyst (E-TEK, 20wt\% Pt). The $\mathrm{Pt} / \mathrm{C}$, known as the best catalyst for HER, exhibits nearly zero onset overpotential $(\eta)$ and a high current density. Our $\mathrm{MoS}_{2} / \mathrm{GR}$ hybrid catalyst showed relatively small $\eta$ of $0.12 \mathrm{~V}$. Since recentlydeveloped best $\mathrm{MoS}_{2}$-based electrocatalysts exhibit $\eta$ of $0.1-$ $0.2 \mathrm{~V}^{32-36}$, we can state that our HMA method can produce one of the best-performing $\mathrm{MoS}_{2}$-based electrocatalysts. In the absence of GR, bare $\mathrm{MoS}_{2}$ exhibits significantly lower activity in terms of $\eta$ (ca. $0.2 \mathrm{~V}$ ) and current density. Commercial $\mathrm{MoS}_{2}$ shows even lower HER activity than bare $\mathrm{MoS}_{2}$. For further investigation of HER activity, polarization results were fitted to Tafel equation $(\eta=a+$ $b \log |J|)$, where $J$ is the current density and $b$ is the Tafel slope. In Figure $6 \mathrm{~b}$, Pt shows $30 \mathrm{mV} / \mathrm{dec}$ of Tafel slope, which is consistent with the reported values. The Tafel slope of $\mathrm{MoS}_{2} / \mathrm{GR}$ hybrid was $50 \mathrm{mV} / \mathrm{dec}$, far outperforming bare $\mathrm{MoS}_{2}(180 \mathrm{mV} / \mathrm{dec})$. Our Tafel slope is somewhat higher than the value reported by Dai et al. for $\mathrm{MoS}_{2} / \mathrm{RGO}$ hybrid $(40 \mathrm{mV} / \mathrm{dec})^{33}$, but comparable to or less than the values obtained using $\mathrm{MoS}_{2} / \mathrm{Au}(111)$ catalyst ${ }^{32}$, core $\left(\mathrm{MoO}_{3}\right)$-shell $\left(\mathrm{MoS}_{2}\right)$ catalyst ${ }^{34}$, and double-gyroid $\mathrm{MoS}_{2}$ catalyst $(55-60 \mathrm{mV} /$ $\mathrm{dec})^{35}$. This indicates that the surface state of our $\mathrm{MoS}_{2} / \mathrm{GR}$ is similar to those of other active $\mathrm{MoS}_{2}$-based catalysts with maximum exposed edges of $\mathrm{MoS}_{2}$ nanocrystals, which have been identified as active sites for $\mathrm{HER}^{32}$. By combining $\mathrm{MoS}_{2}$ and GR, aggregation of $\mathrm{MoS}_{2}$ is markedly reduced compared to bare $\mathrm{MoS}_{2}$, exposing more $\mathrm{MoS}_{2}$ sites available to HER. At the same time, GR provides highly conducting electron pathway to the loaded $\mathrm{MoS}_{2}$ nanocrystals and thus increases the activity of active sites with aid of a strong $\mathrm{MoS}_{2}$-GR interaction. Besides the high activity, synthesized $\mathrm{MoS}_{2} / \mathrm{GR}$ hybrid exhibits very good electrochemical stability. After a thousand potential-cycling tests between -0.3 and $0.2 \mathrm{~V}$, activity loss of $\mathrm{MoS}_{2} / \mathrm{GR}$ is negligible as shown in Figure $6 \mathrm{c}$. Furthermore, the crystalline structure and morphology of the $\mathrm{MoS}_{2} /$ GR were generally conserved after electrochemical stability test (Figure S8). Such a good stability and activity of our $\mathrm{MoS}_{2} / \mathrm{GR}$ electrocatalyst as well as the exceptional speed and energy economy of the fabrication method make the HMA process a viable candidate to manufacture the practical $\mathrm{MoS}_{2}$-based electrocatalysts for HER in a large scale.

To investigate electrochemical characteristics of $\mathrm{MoS}_{2} / \mathrm{GR}$, electrochemical impedance spectroscopy (EIS) measurements were conducted. Figure $6 \mathrm{~d}$ displays the obtained Nyquist plots. The data were fitted with an equivalent circuit shown in the inset of Figure $6 \mathrm{~d}$, and the resultant fitting parameters are summarized in Table 1. A semicircle consisting of charge transfer resistance $\left(\mathrm{R}_{\mathrm{ct}}\right)$ and corresponding capacitance describes the charge-transfer process at the interface between electrocatalyst and electrolyte. In general, $\mathrm{R}_{\mathrm{ct}}$ value is inversely proportional to electrocatalytic activity. The obtained $\mathrm{R}_{\mathrm{ct}}$ value of $\mathrm{MoS}_{2} / \mathrm{GR}(35 \Omega)$ is much lower than those of bare $\mathrm{MoS}_{2}(1130 \Omega)$ and commercial $\mathrm{MoS}_{2}(3600 \Omega)$. Thus, such a lower $\mathrm{R}_{\mathrm{ct}}$ value of $\mathrm{MoS}_{2} / \mathrm{GR}$ indicates that its high electrocatalytic activity for HER is ascribed to the highly conductive GR layers that improve the charge transfer characteristics of $\mathrm{MoS}_{2}$. In addition to the low $\mathrm{R}_{\mathrm{ct}}$ value, $\mathrm{MoS}_{2} / \mathrm{GR}$ exhibits a much higher capacitance value of $1246 \mu \mathrm{F}$ compared to 56.64 and $16.81 \mu \mathrm{F}$ for bare $\mathrm{MoS}_{2}$ and commercial $\mathrm{MoS}_{2}$, respectively. By combining GR and $\mathrm{MoS}_{2}$, the aggregation of $\mathrm{MoS}_{2}$ is significantly reduced as confirmed by TEM/SEM analyses. More

Table 2 | Structural parameters calculated from Mo K-edge EXAFS fits for $\mathrm{MoS}_{2}$ catalysts

\begin{tabular}{|c|c|c|c|c|c|c|c|c|c|c|}
\hline \multirow[b]{2}{*}{ catalysts } & \multicolumn{3}{|c|}{ Mo-S } & \multicolumn{6}{|c|}{ Mo-Mo } & \multirow[b]{2}{*}{$R$-factor } \\
\hline & $\mathrm{N}^{a}$ & $R\left({ }^{\mathrm{A}}\right)^{\mathrm{b}}$ & $\sigma^{2}\left(\AA^{2}\right)^{c}$ & $N_{1}^{a}$ & $R_{1}\left(\AA^{b}\right)^{b}$ & $\sigma_{1}{ }^{2}\left(\AA^{2}\right)^{c}$ & $\mathrm{~N}_{2}{ }^{\mathrm{a}}$ & $R_{2}(\AA)^{b}$ & $\sigma_{2}^{2}\left(\AA^{2}\right)^{c}$ & \\
\hline 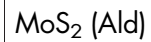 & 6.0 & $2.41(1)$ & $0.003(1)$ & - & - & - & $6.0 *$ & $3.17(1)$ & $0.002(1)$ & 0.004 \\
\hline $\mathrm{MoS}_{2}$ & $4.2(4)$ & $2.38(1)$ & $0.008(2)$ & $2.1(5)$ & $2.75(2)$ & $0.012(5)$ & $0.2(2)$ & $3.16(2)$ & $<0.001(5)^{* *}$ & 0.016 \\
\hline $\mathrm{MoS}_{2} / \mathrm{GR}$ & $3.8(4)$ & $2.40(1)$ & $0.005(1)$ & $2.2(6)$ & $2.82(3)$ & $0.014(5)$ & $1.6(5)$ & $3.16(2)$ & $0.006(1)$ & 0.006 \\
\hline
\end{tabular}

${ }^{a}$ coordination number, ${ }^{b}$ bond distance, ${ }^{c}$ Debye-Waller factor, d a sum-of-squares measure of the fractional misfit.

*fixed parameter, $* *$ a very small value due to weak correlation with the small coordination number.

The number in parentheses denotes an uncertainty of the calculated parameter at the last digit place. 

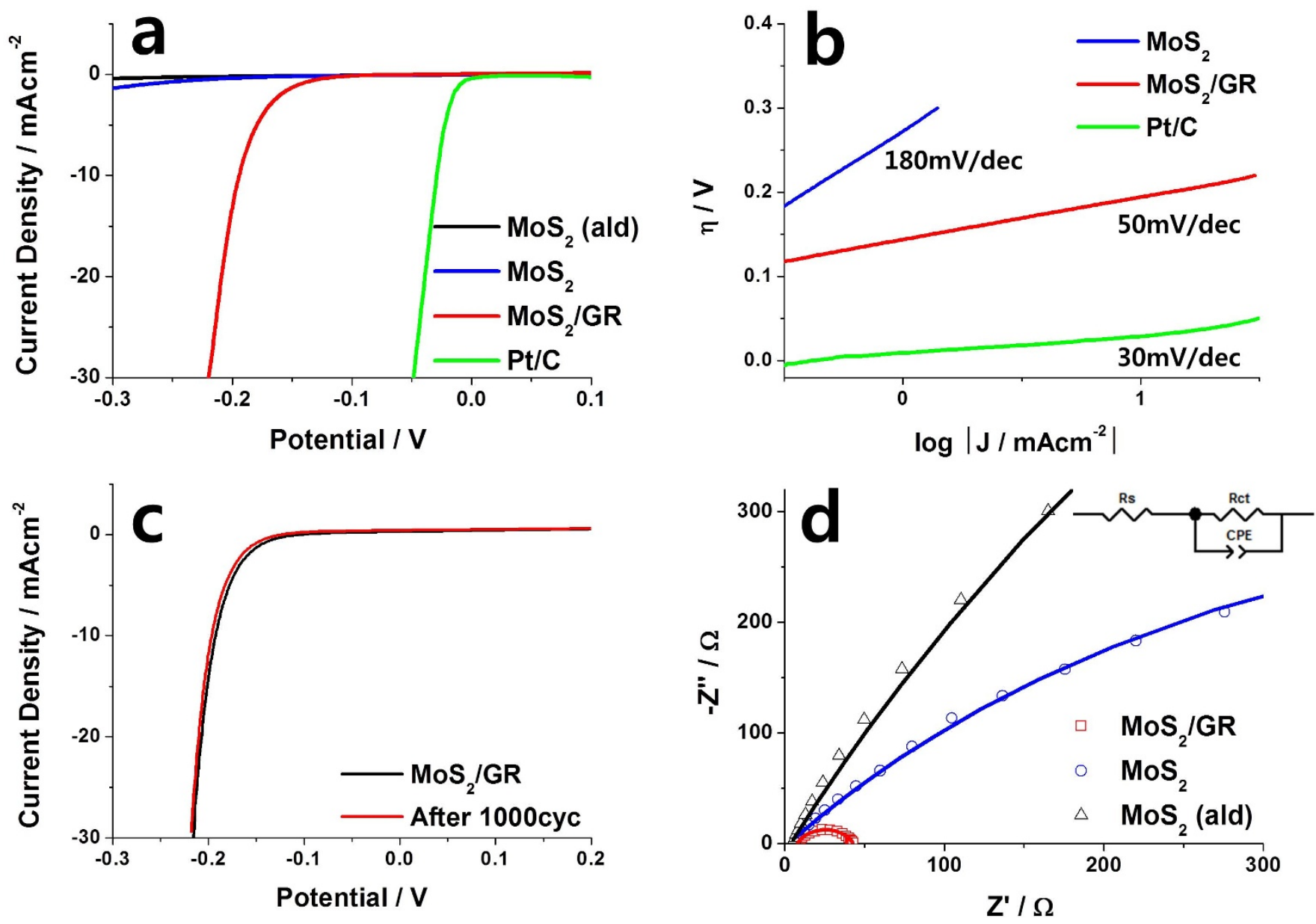

Figure 6 Electrochemical characterization of prepared catalysts. (a) polarization curves, (b) Tafel plots, (c) stability measurements, and (d) Nyquist plots. Inset of $(\mathrm{d})$ depicts the equivalent circuit.

$\mathrm{MoS}_{2}$ nanocrystals could be in contact with electrolyte and thus could participate in HER. The EIS results confirm that the enhanced activity of $\mathrm{MoS}_{2} / \mathrm{GR}$ originates from two main factors; i) increased activity of each active site by improved charge transfer characteristics and ii) increased number of active sites accessible by electrolyte by dispersing $\mathrm{MoS}_{2}$ particles on graphene layers. In both cases, GR plays crucial roles by revealing its excellent electron conductivity and minimizing the aggregation of $\mathrm{MoS}_{2}$ nanocrystals. In addition, it is a good microwave absorber and assists the HMA process in formation of $\mathrm{MoS}_{2}$ crystals.

\section{Discussion}

In this report, we have synthesized $\mathrm{MoS}_{2} / \mathrm{GR}$ hybrid catalyst for HER by a new method of hybrid microwave annealing. Herein, the graphite susceptor initiates the formation of $\mathrm{MoS}_{2}$ nanocrystals and reduction of graphene oxide by transferring heat to the reaction system. The thermally reduced graphene further facilitates the reaction by effectively absorbing the microwave and transmitting the heat to $\mathrm{MoS}_{2}$ crystals. The process produces the highly crystalline $\mathrm{MoS}_{2}$ in the second-scale (only 45 seconds in the present case) by irradiation using a $1000 \mathrm{~W}$ household microwave oven. Thus our synthetic method is ultrafast and energy-economic. Note that the general synthetic methods of $\mathrm{MoS}_{2}$ involve various steps including sulfurization using $\mathrm{H}_{2} \mathrm{~S}$ gas, hydrothermal or solvothermal treatment requiring high temperatures and more than hour-scale heat treatment. Thus, we could conclude that our synthetic method of $\mathrm{MoS}_{2} / \mathrm{GR}$ hybrid electrocatalyst has the following advantages: i) Reduction of GO to GR occurs simultaneously with the crystallization of $\mathrm{MoS}_{2}$. ii)
Additional loading step of $\mathrm{MoS}_{2}$ on GR is not required. iii) Thermal treatment time is extremely short, thus this process is simple, ultrafast and energy-economic. iv) Scale up is very easy. Furthermore the $\mathrm{MoS}_{2} / \mathrm{GR}$ composite synthesized by our method exhibits high HER activity with small $\eta$ of $0.12 \mathrm{~V}$ and Tafel slope of $50 \mathrm{mV} / \mathrm{dec}$. This performance represents one of the best among reported $\mathrm{MoS}_{2}$-based electrocatalysts for HER. In addition, it exhibits an excellent stability under repeated potential cycling tests. The enhanced electrochemical properties of $\mathrm{MoS}_{2} / \mathrm{GR}$ are attributed to the increased activity of active $\mathrm{MoS}_{2}$ sites and increased number of the sites by excellent conducting and textural properties of graphene.

\section{Methods}

Catalysts preparation. Graphene oxide (GO) prepared by Hummer's method ${ }^{53}$ was ultrasonically dispersed in $20 \mathrm{ml}$ ethanol. $1 \mathrm{~g} \mathrm{MoCl}_{5}$ was dissolved in $2.53 \mathrm{ml}$ of ethanol, which was added to GO-containing solution. Stoichiometic amount of thiourea $(560 \mathrm{mg}$ ), as a sulfur source, was added to the solution under vigorous stirring. After $1 \mathrm{~h}$ stirring, the solution was dried in an oven to evaporate excess amount of ethanol and irradiated using a $1000 \mathrm{~W}$ household microwave oven for 45 seconds. Followed by washing with excess amount of water and ethanol, we could obtain $\mathrm{MoS}_{2} / \mathrm{GR}$ powder. The final yield of $\mathrm{MoS}_{2}$ was ca. $85-90 \%$. The nominal contents of $\mathrm{MoS}_{2}$ in $\mathrm{MoS}_{2} / \mathrm{GR}$ composite was $75 \mathrm{wt} \%$. As a control experiment, bare $\mathrm{MoS}_{2}$ was synthesized by carrying out the procedure without GO.

Catalysts characterization. Crystalline structures of synthesized catalysts were revealed by X-ray diffraction (XRD, PANalytical PW 3040/60 X'pert), and structural details were investigated by scanning electron microscopy (SEM, JEOL JSM-7410F)/ energy dispersive spectroscopy (EDS) and transmission electron microscopy (Cscorrected HR-STEM, JEOL JEM-2200FS)/electron energy loss microscopy (EELS) at National Center of Nanomaterials Technology (NCNT). Conductivity of the catalysts was measured by the four point probe method (Keithley 2400) using pelletized samples. Reaction mechanism was elucidated using infra-red spectroscopy (IR, 
Nicolet 6700). Chemical states of the catalysts were elucidated with Raman spectroscopy (Alpha 300R, WITEC) and X-ray photoelectron microscopy (XPS, ESCALAB 250Xi)

$\mathrm{X}$-ray absorption fine structure (XAFS) was applied to investigate the local structure of synthesized $\mathrm{MoS}_{2}$ catalysts. The XAFS measurements were conducted on 7D beamline of the Pohang Accelerator Laboratory (PLS-II, 3.0 GeV), Korea. The incident beam was monochromatized using a $\mathrm{Si}$ (111) double crystal monochromator. At room temperature, the spectra were taken for the K-edge of Mo $\left(\mathrm{E}_{0}=\right.$ $20000 \mathrm{eV}$ ) in a transmission mode with separate $\mathrm{N}_{2}$-filled IC Spec ionization chambers for incident and transmitted beams. The obtained data were analyzed with ATHENA and ARTEMIS in the IFEFIT suite of software programs ${ }^{54}$. The reference material used as a standard for fitting experimentally derived radial structural functions (RSF) was generated with Feff9 code using $\beta-\mathrm{MoS}_{2}$ and Mo metal crystal structures $^{55}$

Electrochemical Tests. Electrochemical measurements including linear sweep voltammetry (LSV) and durability tests were carried out in a conventional three electrode cell with $\mathrm{N}_{2}$ purged aqueous solution of $0.5 \mathrm{M} \mathrm{H}_{2} \mathrm{SO}_{4}$ using a potentiostat (Ivium technologies) equipped with a rotaing disk electrode setup (RDE, PAR Model $636 \mathrm{RDE})$. The $\mathrm{Ag} / \mathrm{AgCl}(3 \mathrm{M} \mathrm{NaCl})$ electrode and a $\mathrm{Pt}$ wire were used as reference and counter electrodes, respectively. In this paper, all the potentials were referred to the reversible hydrogen electrode (RHE) without specification. The working electrodes were prepared by dispersing $20 \mathrm{mg}$ of catalyst in $2 \mathrm{ml}$ of deionized water and $40 \mu \mathrm{l}$ of $5 \%$ Nafion solution and pipetting out $15 \mu \mathrm{l}$ of slurry onto a glassy carbon electrode $\left(0.19635 \mathrm{~cm}^{2}\right) .9 \mu$ of Nafion solution was added on top to fix the electrocatalyst. The LSV tests were performed at a scan rate of $5 \mathrm{mV} \mathrm{s}^{-1}$ with $900 \mathrm{rpm}$. The durability tests were carried out by repeating the potential scan from $0.4 \mathrm{~V}$ to $-0.3 \mathrm{~V}$ with 1000 cycles. In the identical cell setup, electrochemical impedance spectroscopy (EIS) was carried out. The frequency range was from $100 \mathrm{kHz}$ to $1 \mathrm{mHz}$ with a modulation amplitude of $10 \mathrm{mV}$ at $-0.2 \mathrm{~V}$ bias voltage. The EIS spectra were fitted by the Z-view software.

1. Balandin, A. A. Thermal properties of graphene and nanostructured carbon materials. Nature Mater. 10, 569-581 (2011).

2. Chen, L., Hernandez, Y., Feng, X. \& Müllen, K. From nanographene and graphene nanoribbons to graphene sheets: chemical synthesis. Angew. Chem. Int. Ed. 51, 7640-7654 (2012).

3. Youn, D. H. et al. A highly efficient transition metal nitride-based electrocatalyst for oxygen reduction reaction: TiN on a CNT-graphene hybrid support. J. Mater. Chem. A 1, 8007-8015 (2013).

4. Yang, J. et al. $\mathrm{LiFePO}_{4}$-graphene as a superior cathode material for rechargeable lithium batteries: impact of stacked graphene and unfolded graphene. Energy Environ. Sci. 6, 1521-1528 (2013).

5. Chen, S., Zhu, J. \& Wang, X. One-step synthesis of graphene-cobalt hydroxide nanocomposites and their electrochemical properties. J. Phys. Chem. C 114, 11829-11834 (2010).

6. Zhang, H., Lv, X., Li, Y., Wang, Y. \& Li, J. P25-graphene composite as a high performance photocatalyst. ACS Nano 4, 380-386 (2009).

7. Youn, D. H. et al. TiN nanoparticles on CNT-graphene hybrid support as noblemetal-free counter electrode for quantum dot-sensitized solar cells. ChemSusChem 6, 261-267 (2013).

8. Bai, H., Li, C. \& Shi, G. Functional composite materials based on chemically converted graphene. Adv. Mater. 23, 1089-1115 (2011).

9. Huang, X., Zeng, Z., Fan, Z., Liu, J. \& Zhang, H. Graphene-based electrodes. Adv. Mater. 24, 5979-6004 (2012).

10. Sun, Y., Wu, Q. \& Shi, G. Graphene based new energy materials. Energy Environ. Sci. 4, 1113-1132 (2011).

11. Cao, A. et al. A facile one-step method to produce graphene-CdS quantum dot nanocomposites as promising optoelectronic materials. Adv. Mater. 22, 103-106 (2010).

12. Bashkova, S. \& Bandosz, T. J. Adsorption/reduction of $\mathrm{NO}_{2}$ on graphite oxide/ iron composites. Ind. Eng. Chem. Res. 48, 10884-10891 (2009).

13. Zhang, L.-S. et al. Mono dispersed $\mathrm{SnO}_{2}$ nanoparticles on both sides of single layer graphene sheets as anode materials in Li-ion batteries. J. Mater. Chem. 20, 5462-5467 (2010)

14. Menezes, R. R., Souto, P. M. \& Kiminami, R. H. G. A. [Microwave fast sintering of ceramic materials] Sintering of Ceramics - New Emerging Techniques [Lakshmanan A. (ed.)] [3-26] (Intech, Rijeka, 2012).

15. Chang, K.-H. et al. A unique strategy for preparing single-phase unitary/binary oxides-graphene composites. Chem. Commun. 46, 7957-7959 (2010).

16. Bai, S. et al. Optical Properties and a simple and general route for the rapid syntheses of reduced graphene oxide-metal sulfide nanocomposites. Eur. J. Inorg. Chem. 2013, 256-262 (2013).

17. Brosnan, K. H., Messing, G. L. \& Agrawal, D. K. Microwave sintering of alumina at 2.45 GHz. J. Am. Ceram. Soc. 86, 1307-1312 (2003).

18. Oghbaei, M. \& Mirzaee, O. Microwave versus conventional sintering: A review of fundamentals, advantages and applications. J. Alloys Compd. 494, 175-189 (2010).

19. Prabhu, G., Chakraborty, A. \& Sarma, B. Microwave sintering of tungsten. Int. J. Refract. Met. Hard Mater. 27, 545-548 (2009).
20. Breval, E. et al. Comparison between microwave and conventional sintering of WC/Co composites. Mater. Sci. Eng. A 391, 285-295 (2005).

21. Saitou, K. Microwave sintering of iron, cobalt, nickel, copper and stainless steel powders. Scripta Mater. 54, 875-879 (2006).

22. Cheng, J., Agrawal, D., Zhang, Y. \& Roy, R. Microwave sintering of transparent alumina. Mater. Lett. 56, 587-592 (2002).

23. Wang, Q. H., Kalantar-Zadeh, K., Kis, A., Coleman, J. N. \& Strano, M. S. Electronics and optoelectronics of two-dimensional transition metal dichalcogenides. Nature Nanotech. 7, 699-712 (2012).

24. Lauritsen, J. V. et al. Hydrodesulfurization reaction pathways on $\mathrm{MoS}_{2}$ nanoclusters revealed by scanning tunneling microscopy. J. Catal. 224, 94-106 (2004).

25. Woo, H., Kirn, Y., Nam, I.-S., Chung, J. \& Lee, J. Oxidized $\mathrm{K}_{2} \mathrm{CO}_{3} / \mathrm{MoS}_{2}$ as a novel sulfur-resistant catalyst for Fischer-Tropsch reaction. Catal. Lett. 20, 221-229 (1993).

26. Chang, K. \& Chen, W. In situ synthesis of $\mathrm{MoS}_{2}$ /graphene nanosheet composites with extraordinarily high electrochemical performance for lithium ion batteries. Chem. Commun. 47, 4252-4254 (2011).

27. Radisavljevic, B., Radenovic, A., Brivio, J., Giacometti, V. \& Kis, A. Single-layer $\mathrm{MoS}_{2}$ transistors. Nature Nanotech. 6, 147-150 (2011).

28. Xiang, Q., Yu, J. \& Jaroniec, M. Synergetic effect of $\mathrm{MoS}_{2}$ and graphene as cocatalysts for enhanced photocatalytic $\mathrm{H}_{2}$ production activity of $\mathrm{TiO}_{2}$ nanoparticles. J. Am. Chem. Soc. 134, 6575-6578 (2012).

29. Lin, J.-Y., Chan, C.-Y. \& Chou, S.-W. Electrophoretic deposition of transparent $\mathrm{MoS}_{2}$-graphene nanosheet composite films as counter electrodes in dyesensitized solar cells. Chem. Commun. 49, 1440-1442 (2013).

30. Bonde, J., Moses, P. G., Jaramillo, T. F., Norskov, J. K. \& Chorkendorff, I. Hydrogen evolution on nano-particulate transition metal sulfides. Faraday Discuss. 140, 219-231 (2009).

31. Chang, Y.-H. et al. Highly efficient electrocatalytic hydrogen production by $\mathrm{MoS}_{\mathrm{x}}$ grown on graphene-protected 3D Ni foams. Adv. Mater. 25, 756-760 (2013).

32. Jaramillo, T. F. et al. Identification of active edge sites for electrochemical $\mathrm{H}_{2}$ evolution from $\mathrm{MoS}_{2}$ nanocatalysts. Science 317, 100-102 (2007).

33. Li, Y. et al. $\mathrm{MoS}_{2}$ nanoparticles grown on graphene: An advanced catalyst for the hydrogen evolution reaction. J. Am. Chem. Soc. 133, 7296-7299 (2011).

34. Chen, Z. et al. Core-shell $\mathrm{MoO}_{3}-\mathrm{MoS}_{2}$ nanowires for hydrogen evolution: A functional design for electrocatalytic materials. Nano Lett. 11, 4168-4175 (2011).

35. Kibsgaard, J., Chen, Z., Reinecke, B. N. \& Jaramillo, T. F. Engineering the surface structure of $\mathrm{MoS}_{2}$ to preferentially expose active edge sites for electrocatalysis. Nature Mater. 11, 963-969 (2012).

36. Firmiano, E. G. S. et al. Graphene oxide as a highly selective substrate to synthesize a layered $\mathrm{MoS}_{2}$ hybrid electrocatalyst. Chem. Commun. 48, 7687-7689 (2012).

37. Giordano, C. et al. Synthesis of Mo and W Carbide and Nitride Nanoparticles via a Simple Urea Glass Route. Nano Lett. 8, 4659-4663 (2008).

38. Pei, S. \& Cheng, H.-M. The Reduction of Graphene Oxide. Carbon 50, 3210-3228 (2012).

39. Singh, V. K. et al. Microwave absorbing properties of a thermally reduced graphene oxide/nitrile butadiene rubber composite. Carbon 50, 2202-2208 (2012).

40. Wang, H. et al. Nanocrystal growth on graphene with various degrees of oxidation. J. Am. Chem. Soc. 132, 3270-3271 (2010).

41. Wang, H. et al. $\mathrm{Mn}_{3} \mathrm{O}_{4}$-graphene hybrid as a high capacity anode material for lithium ion batteries. J. Am. Chem. Soc. 132, 13978-13980 (2010).

42. Liang, Y. Y. et al. $\mathrm{TiO}_{2}$ nanocrystals grown on graphene as advanced photocatalytic hybrid materials. Nano Res. 3, 701-705 (2010).

43. Thongtem, T., Phuruangrat, A. \& Thongtem, S. Synthesis and analysis of CuS with different morphologies using cyclic microwave irradiation. J. Mater. Sci. 42, 9316-9323 (2007).

44. Kumari, R. G. et al. Raman spectral investigation of thiourea complexes. Spectrochim. Acta Part A 73, 263-267 (2009).

45. Jang, J.-W. et al. Photocatalytic synthesis of pure and water-dispersible graphene monosheets. Chem. Eur. J. 18, 2762-2767 (2012).

46. Kundu, A., Layek, R. K., Kuila, A. \& Nandi, A. K. Highly fluorescent graphene oxide-poly(vinyl alcohol) hybrid: An effective material for specific $\mathrm{Au}^{3+}$ ion sensors. ACS Appl. Mater. Interfaces 4, 5576-5582 (2012).

47. Stankovich, S. et al. Synthesis of Graphene-based Nanosheets via Chemical Reduction of Exfoliated Graphite Oxide. Carbon 45, 1558-1565 (2007).

48. Cui, P. et al. One-pot Reduction of Graphene Oxide at Subzero Temperatures. Chem. Commun. 47, 12370-12372 (2011).

49. Choi, E.-Y. et al. Noncovalent Functionalization of Graphene with End-functional Polymers. J. Mater. Chem. 20, 1907-1912 (2010)

50. Wang, P.-P., Sun, H., Ji, Y., Li, W. \& Wang, X. Three-Dimensional Assembly of Single-Layered $\mathrm{MoS}_{2}$. Adv. Mater. 26, 964-969 (2013).

51. Hassel, O. Ueber die Kristallstruktur des Molybdaenglanzes. Z. Kristallogr. 61, 92-99 (1925).

52. Haskel, D. et al. XAFS study of local disorder in the a- $\mathrm{Gd}_{\mathrm{x}} \mathrm{Si}_{1-\mathrm{x}}$ amorphous magnetic semiconductor. Phys. Rev. B 67, 115207 (2003).

53. Hummers, W. S. \& Offeman, R. E. Preparation of graphitic oxide. J. Am. Chem. Soc. 80, 1339-1339 (1958).

54. Ravel, B. \& Newville, M. ATHENA, ARTEMIS, HEPHAESTUS: Data analysis for $\mathrm{X}$-ray absorption spectroscopy using IFEFFIT. J. Synchrotron Rad. 12, 537-541 (2005). 
55. Rehr, J. J., Kas, J. J., Vila, F. D., Prange, M. P. \& Jorissen, K. Parameter-free calculations of X-ray spectra with FEFF9. Phys. Chem. Chem. Phys. 12, 5503-5513 (2010).

\section{Acknowledgments}

This work has been supported by BK Plus Program, Basic Science Research Program (No. 2012-017247), and Korea Center for Artificial Photosynthesis (KCAP) located in Sogang University funded by the Ministry of Science, ICT and Future Planning (MSIP) through the National Research Foundation of Korea (No. 2009-0093880).

\section{Author contributions}

D.H.Y. and J.-W.J. designed and performed the experiments. J.Y.K. helped to measure and analyze the EIS data. J.S.J. and S.H.C. helped to perform the XAS measurements and analyzed the EXAFS data. J.S.L. supervised the project.

\section{Additional information}

Reprints and permission information is available online at http://npg.nature.com/ reprintsandpermissions/

Supplementary information accompanies this paper at http://www.nature.com/ scientificreports

Competing financial interests: The authors declare no competing financial interests.

How to cite this article: Youn, D.H. et al. Fabrication of graphene-based electrode in less than a minute through hybrid microwave annealing. Sci. Rep. 4, 5492; DOI:10.1038/ srep05492 (2014).

(c) (i) (2) This work is licensed under a Creative Commons Attribution-NonCommercialShareAlike 4.0 International License. The images or other third party material in thi article are included in the article's Creative Commons license, unless indicated otherwise in the credit line; if the material is not included under the Creative Commons license, users will need to obtain permission from the license holder in order to reproduce the material. To view a copy of this license, visit http:// creativecommons.org/licenses/by-nc-sa/4.0/ 